\title{
Enabling the Quality of Care for Older People
}

\author{
Jason L Powell* \\ Department of Social and Political Sci, United Kingdom

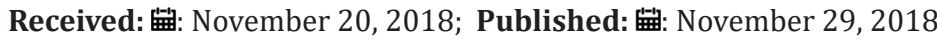 \\ *Corresponding author: Jason L Powell, Department of Social and Political Science,United Kingdom
}

\section{Mini Review}

There has been a raft of research recently on the care of older people. Many of them take a theoretical approach and many take a policy approach. These books are huge in scope and a survey of them would suggest they are comparative mainly in the United States and United Kingdom. For many years, ageism prevented books from being written on older people because of the intense interest of children by practitioners. This is not to deny the importance and significance of that group of people at one end of the life-course. Historically, to suggest "age" instantly meant younger people added to the marginality and invisibility of older people. Worse, because there were hardly any widely subscribed postgraduate courses in social work in working with older people, with the overwhelming focus on children, there were periodic episodes of inhumanity against older people (known today as "elder abuse"). It was a forgotten dimension that older people were people. There was also a chronic shortage of research and knowledge for careers, families, health and social work professions on the vulnerabilities of older people whether if they lived at home or lived in a care home. Peter Townsend wrote his devastating overview of "care" in his famous book "The Last Refuge" (1959) that care homes were not necessarily benevolent institutions, but 'warehouses' were care was in chaos as careers did not have the enough skills, knowledge and practice to work with older people.

Hence, whilst these research base on policy and theory in caring for older people are important, practice with older people has been overlooked. This is a magnificent piece of writing. The reasons are utterly compelling highlighting to careers, helping and health professions the implications and opportunities to care with, care for and care about older people. Practitioners really need to excel in that there is no duality in terms of thinking about practice and doing practice. For a long time, in a discipline called Social Gerontology, there was a demarcation between thinkers and doers. Authors used to implicitly suggest there was some form of exaggerated age wars between thinkers and those who investigate older people's experiences (do-errs). The importance of deconstructing and obliterating such assumptions and with an intellectual wallop synthesizing the importance of thinking and doing for effective practice transcending ethnocentric and Eurocentric approaches to care is a necessity. I have rarely read a literature on care of older people that addresses exploring thinking tools and doing practice as a dualism. They are two sides of the same coin, not in opposition.

The ability to shed light on the importance of valuing older people is also essential. This prevents and should provide some sensitivity to careers in recognizing that older people are people with human rights. Recent research lumps 'older people' into an undifferentiated category as though it's not differentiated by race, gender, sexuality, disability, class and history. Engaging in research with older people is one of those rare attempts in social research that gets the researcher and practitioners to engage from the beginning to the end and beyond. I say beyond, because after I read the current literature on caring for older people it got me to think about the assumptions I had about older people and implore researchers to think deep and focus on what is means to be cared for and cared by a variety of people and professions. Research is needed in getting social and health policy makers to transform their attitudes. This means engaging with service providers to addresses social divisions head on and context sensitive situations where people learn from working with older people. 


\section{ISSN: 2574-1241}

DOI: 10.26717/BJSTR.2018.11.002115

Jason L Powell. Biomed J Sci \& Tech Res

This work is licensed under Creative

Commons Attribution 4.0 License

Submission Link: https://biomedres.us/submit-manuscript.php

\begin{tabular}{ll} 
BIOMEDICAL & Assets of Publishing with us \\
RESEARCHES & - Global archiving of articles \\
& - Immediate, unrestricted online access \\
\hline
\end{tabular}

